\title{
Dispatch and prehospital transport for acute septic patients: an observational study
}

Peter Bank Pedersen ${ }^{1 *}$, Daniel Pilsgaard Henriksen², Søren Mikkelsen ${ }^{3}$ and Annmarie Touborg Lassen ${ }^{4}$

\begin{abstract}
Background: In order to dispatch ambulances with the correct level of urgency, the dispatch center has to balance the perceived urgency and traffic safety considerations with the available resources. As urgency is not clear in all clinical situations, some high urgency patients may end up with a suboptimal mode of transport. Patients with severe sepsis or septic shock suffer from highly time dependent conditions but they present with a wide range of symptoms, which might be difficult to identify in the dispatch system.

The aim of the study is to investigate the modes of prehospital transport among acute admitted patients with sepsis, severe sepsis and septic shock.

Methods: We included all adult patients ( $\geq 15$ years) presenting to an acute medical unit at Odense University Hospital with a first-time admission of community-acquired sepsis between September 2010-August 2011. Cases and prehospital ambulance transport were identified by structured manual chart review. In all cases it was registered, whether the ordinary ambulance was assisted by the mobile emergency care unit (MECU), manned by anesthesiologists.
\end{abstract}

Results: We included 1,713 patients median age 72 years (IQR 57-81), 793 (46.3\%) male, 621 (36.3\%) had sepsis, 1,071 (62.5\%) severe sepsis, and 21 (1.2\%) septic shock.

In the group of sepsis patients, 390 (62.8\%) arrived without public prehospital transport, 197 (31.7\%) were transported by ambulance, and 34 (5.5\%) were assisted by MECU. In the group of severe sepsis patients, the same percentage 62.8\% arrived without public pre-hospital transport, a lower percentage $28.2 \%$ were transported by ambulance, and a larger percentage 9.0\% were transported by MECU. Among 21 patients with septic shock, 10 arrived without public pre-hospital transport (47.7\%), 7 (33.3\%) were transported by ambulance, and 4 (19.0\%) by MECU.

The 30-day mortality hazard ratio was associated with mode of transport, with the adjusted highest hazard ratio found in the group of MECU transported patients 1.76 (95\%Cl 1.16-2.66).

Conclusions: A substantial proportion of patients with severe sepsis and septic shock arrive to hospital without public prehospital transport or by unspecialized ambulances.

Keywords: Prehospital transport, Dispatch, Sepsis, Septic shock, Emergency medicine, Acute medicine

\footnotetext{
* Correspondence: peter.bank.pedersen@rsyd.dk

${ }^{1}$ Department of Emergency Medicine, Institute of Clinical Research, University

of Southern Denmark \& Odense University Hospital, Odense C DK-5000,

Denmark

Full list of author information is available at the end of the article
} 


\section{Background}

Emergency medical dispatchers are gatekeepers for prehospital emergency care and receive calls from patients or bystanders [1]. Optimal dispatch of prehospital patient transport is a balance between expected urgency, considerations pertaining to traffic safety and available resources. Patients need different levels of transport, from patients with life threatening conditions, which require immediate response by mobile emergency care units (MECU), to patients who attend the hospital without public prehospital transport. The response from the dispatch system is based at descriptions of symptoms and conditions, and aim to identify patients with an acute lifethreatening condition, who should receive a more rapid ambulance response, than patients with a non-acute condition [2]. The aim is that the correct mode of transportation is dispatched to all patients at all time [3]. However, urgency is not clear in all clinical situations, and therefore some high urgency patients end up with a suboptimal mode of transport [4].

Patients with severe sepsis, which is a life-threatening organ dysfunction caused by a dysregulated host response to infection, or septic shock, suffers a highly time dependent condition. [5-7]. As septic patients present with a wide range of symptoms, it can be difficult to identify them in the dispatch as well as in the hospital system $[5,8,9]$.

The aim of the study is to present the mode of prehospital transport among acute admitted patients with sepsis, severe sepsis and septic shock. We hypothesized that mode of prehospital transport was independent of sepsis severity at arrival to hospital.

\section{Methods}

This study is a hospital based observational study based on registration of all acute medical hospital contacts and MECU transports to the hospital in combination with chart reviews of all acute medical patients. All patients who arrived with sepsis, severe sepsis or septic shock were identified by post-hoc diagnosis. The identification methods have previously been described in details [10-15].

\section{Setting}

The Danish healthcare system is tax-funded and provides free healthcare for all residents. Odense University Hospital serves as a primary hospital for a population of 290.000 persons.

The acute medical unit had all acute admitted medical patients, referred either from a primary care physician or from the open general emergency department. Exceptions were patients with suspected intracranial thrombosis or hemorrhage, with severe cardiac disease, in hemodialysis, patients in chemotherapy or radiation therapy, or women in active labour.

\section{Patients}

We included all adult patients ( $\geq 15$ years) admitted to an acute medical unit at Odense University Hospital, Denmark, catchment area with maximum distance approximately $40 \mathrm{~km}$, in a 1 year period from September 2010, to August 2011. All contacts were evaluated by a structured manual chart review of the electronic patient file. All patients with sepsis, severe sepsis and septic shock were identified based on predefined criteria of their symptoms at arrival, in combination with results of laboratory findings, cultures and other diagnostics within the first $48 \mathrm{~h}$ after arrival [16].

Patients with sepsis of any severity, who died in the open general ED, were included as well. Patients hospitalized up to 7 days before the current admission were not included to exclude possible hospital-acquired infection. Patients transferred from other hospitals, and patients residing outside the hospitals catchment area at the time of admission, were excluded [10].

Using the unique Danish personal identification number [17], supplemental information was retrieved from the Civil Registration System in Denmark [18] and The Danish National Patient Register [19].

Type of prehospital transport was identified by electronic registration of all MECU transports and information linked at personal level by the unique personal identification number. Ambulance transports were registered by an identification paper, filled by the emergency medical technicians. In all cases where there was no identification of prehospital MECU or ambulance transport we performed a structured manual review of the electronic patient files, where we identified any copy of the ambulance file (optional to store) or other registrations regarding mode of transport.

\section{Definitions}

Systemic inflammatory response syndrome (SIRS) definition: At least two of the following criteria: Temperature $>38{ }^{\circ} \mathrm{C}$ or $<36{ }^{\circ} \mathrm{C}$, pulse $>90$ beats $/$ min, respiratory rate $>20$ breaths $/ \mathrm{min}$ or $\mathrm{PaCO} 2<4,3 \mathrm{kPa}$ (<33 mmHg), leukocyte $>12 \times 10 \mathrm{mia} / \mathrm{L}$ or $<4 \times 10 \mathrm{mia} / \mathrm{L}$. The vital signs used were baseline measurements.

Sepsis was SIRS plus a documented or suspected infection. Severe sepsis was sepsis and at least one organ dysfunction. Septic shock was the occurrence of sepsis plus a systolic blood pressure $\leq 90 \mathrm{mmHg}$ and a lactate $>4,0 \mathrm{mmol} / \mathrm{L}$ within $4 \mathrm{~h}$ after arrival to the hospital or the use of vasopressor agents within the first $24 \mathrm{~h}$ after arrival [10].

\section{Analysis}

Data were presented as proportions with 95\% confidence intervals or median and interquartile range as appropriate. 
Patients were included at their first visit with severe infection within the period. Patients were followed until death, emigration, or 30 days after admission, whichever came first.

We categorized patients into sepsis, severe sepsis or septic shock and categorized prehospital transport into MECU-assisted transportation or ordinary ambulance. If no prehospital mode of transport could be identified, we categorized the patients as attending the hospital without public prehospital transport.

With the aim to describe an alternative estimate of severity of disease and prehospital transport mode, we presented two Cox proportional hazard regression models where the outcome of interest was all-cause mortality within 30 days mode of transport. We presented two models: (i) A crude analysis, (ii) A multivariable analysis adjusted for age and gender, and a multivariable analysis adjusted for all of the remaining potential risk factors (fully adjusted model), dichotomous variables were set as 'not present' or 'within normal range' if missing. Statistical analyses were performed with Stata version 14.1 (Stata Corporation LP, TX). The reporting of this study conforms to the reporting of observational studies in epidemiology statement [20].

\section{Results}

We included 1,713 patients with sepsis of any severity, 793 (46.3\%) were male. The median age was 72 years (IQR 57-81). The predominant site of infection was the lower respiratory tract $(62.9 \%)$, and the most prevalent site of organ failure was the lungs.

Among the 1,713 included patients with sepsis at any severity, 621 patients (36.3\%) had sepsis, 1,071 patients (62.5\%) severe sepsis, and 21 patients (1.2\%) septic shock.

Patients who were transported by MECU more often had bacteremia, central nervous infection and central nervous system failure, metabolic failure or coagulation failure as site of organ failure (Table 1).

We found that, in the group of patients with sepsis, 390 (62.8\%, 95\%CI 58.9-66.6\%) arrived without public prehospital transport, 197 (31.7\%, 95\%CI 28.1-35.5\%) were transported by ambulance, and 34 (5.5\%, 95\%CI $3.8-7.7 \%)$ were assisted by MECU. In the severe sepsis patients group, the same percentage $62.8 \%$ (95\%CI 59.9$65.7 \%)$ arrived without public pre-hospital transport, a lower percentage $28.2 \%$ (95\%CI 25.5-31.0\%) were transported by ambulance, and a larger percentage $9.0 \%$ (95\%CI 7.3-10.8\%) were transported by MECU compared to the sepsis group.

Among 21 patients with septic shock, 10 arrived without public pre-hospital transport $(47.7 \%$, 95\% CI 59.9-65.7\%), 7 (33.3\%, 95\%CI 14.6-57.0\%) were transported by ambulance, and $4(19.0 \%$, 95\%CI $5.4-$ 41.9\%) by MECU (Fig. 1).
For all 1,713 patients with sepsis at any severity, the 30-day mortality for patients arriving without public prehospital transport was $12.7 \%$; arriving with ambulance $16 \%$ and assisted by MECU $20.9 \%$. In the sepsis group, the 30-day mortality was $6.2,5.6$ and $8.8 \%$ in the group with severe sepsis 30-day mortality was 16.2, 23.2, and $22.9 \%$ and in the group of septic shock 30-day mortality was $50.0,12.5$, and $37.5 \%$.

The 30-day mortality hazard ratio was associated with mode of transport, with the highest hazard ratio found in the group of MECU transported patients followed by the group of ambulance-transported patients, and the lowest hazard ratio were seen in the patients arriving without public prehospital transport (Table 2).

\section{Discussion}

We found that, among patients with sepsis of any severity, $63 \%$ arrived without public prehospital transport, $29 \%$ by ambulance, while $8 \%$ were assisted by the MECU. We found no clear association between disease severity and mode of transport in the group of patients transported by ambulance, but the ratio of patients transported by MECU increased by disease severity, and the percentage of patients arriving without public prehospital transport decreased by disease severity (Fig. 1). Other studies have described prehospital transport of septic patients in which transportation was classified as Emergency Medical Service (EMS) or non-EMS. In accordance with this study, they found a high percentage of septic patients transported as non-EMS, $49-59 \%$ [21-23]. One study of severe septic patients classified $78 \%$ as EMS transported patients [24] in contrast to our findings where $37 \%$ were transported by Ambulance or MECU. Although, the Danish healthcare system is free, some patients bypass the dispatch system or public prehospital transport, and arrive on their own accord. In contrast to other diseases as trauma [25], cardiac arrest [26, 27], acute myocardial infarction [28] and stroke [29, 30], septic patients, to a lesser extent, arrived by public prehospital transport. In our study, part of the explanation for patients arriving without public pre-hospital transport could be the short distances with low traffic load.

Sepsis has not benefited from the same public focus, as stroke and acute coronary syndromes have [31], and this may explain why these patients are not, to a greater extent, aware of sepsis. Due to the often non-specific presentations of sepsis, it remains challenging. Although screening tools deriving from emergency medical systems data have been developed, these have yet to be incorporated into daily practice [32]. In one study, nonspecific diagnosis accounted for one-third of the patients transported by ambulance [33], and the most frequent category were "unclear problems", when dispatchers 
Table 1 Baseline characteristics of sepsis patients arriving without public prehospital transport, ambulance or MECU to an Acute Medical Unit in a 1-year period

\begin{tabular}{|c|c|c|c|c|c|}
\hline Mode of transport & & $\begin{array}{l}\text { All } \\
\mathrm{N}\end{array}$ & $\begin{array}{l}\text { Without public } \\
\text { prehospital transport }\end{array}$ & Ambulance & MECU \\
\hline \multirow[t]{3}{*}{ Sex } & Total & 1713 & $(n=1,073)$ & $(n=506)$ & $(n=134)$ \\
\hline & Female & 920 & $601(56.0 \%)$ & $251(49.6 \%)$ & $68(50.7 \%)$ \\
\hline & Male & 793 & $472(44.0 \%)$ & $255(50.4 \%)$ & $66(49.3 \%)$ \\
\hline \multirow[t]{3}{*}{ Age in age categories, years } & $15-39$ & 633 & $437(40.7 \%)$ & $153(30.2 \%)$ & $43(32.1 \%)$ \\
\hline & $40-64$ & 815 & $464(43.2 \%)$ & $280(55.3 \%)$ & $71(53.0 \%)$ \\
\hline & $65-84$ & 265 & $172(16.0 \%)$ & $73(14.4 \%)$ & $20(14.9 \%)$ \\
\hline \multirow[t]{3}{*}{ Charlson Comorbidity Index } & 0 & 570 & $394(36.7 \%)$ & $140(27.7 \%)$ & $36(26.9 \%)$ \\
\hline & 1 & 415 & $240(22.4 \%)$ & $136(26.9 \%)$ & $39(29.1 \%)$ \\
\hline & $>2$ & 728 & $439(40.9 \%)$ & $230(45.5 \%)$ & $59(44.0 \%)$ \\
\hline \multirow[t]{2}{*}{ Immunosuppression } & No & 1362 & $863(80.4 \%)$ & $400(79.1 \%)$ & 99 (73.9\%) \\
\hline & Yes & 351 & $210(19.6 \%)$ & $106(20.9 \%)$ & $35(26.1 \%)$ \\
\hline \multirow[t]{3}{*}{ Sepsis severity } & Sepsis & 621 & $390(36.3 \%)$ & $197(38.9 \%)$ & $34(25.4 \%)$ \\
\hline & Severe sepsis & 1071 & $673(62.7 \%)$ & $302(59.7 \%)$ & $96(71.6 \%)$ \\
\hline & Septic shock & 21 & $10(0.9 \%)$ & $7(1.4 \%)$ & $4(3.0 \%)$ \\
\hline \multirow[t]{2}{*}{ Bacteremia } & No & 1541 & $967(90.1 \%)$ & $460(90.9 \%)$ & $114(85.1 \%)$ \\
\hline & Yes & 172 & $106(9.9 \%)$ & $46(9.1 \%)$ & $20(14.9 \%)$ \\
\hline \multirow[t]{3}{*}{ Number of sources of infection per patient } & 1 & 1453 & $910(84.8 \%)$ & $428(84.6 \%)$ & $115(85.8 \%)$ \\
\hline & 2 & 242 & $152(14.2 \%)$ & $73(14.4 \%)$ & $17(12.7 \%)$ \\
\hline & 3 & 18 & $11(1.0 \%)$ & $5(1.0 \%)$ & $2(1.5 \%)$ \\
\hline \multirow[t]{9}{*}{ Sites of infection } & Lower respiratory tract & 1077 & $636(59.3 \%)$ & $339(67.0 \%)$ & $102(76.1 \%)$ \\
\hline & Urinary tract & 415 & $273(25.4 \%)$ & $113(22.3 \%)$ & $29(21.6 \%)$ \\
\hline & Abdominal & 184 & $129(12.0 \%)$ & $49(9.7 \%)$ & $6(4.5 \%)$ \\
\hline & Skin, muscles, bones & 98 & $78(7.3 \%)$ & $17(3.4 \%)$ & $3(2.2 \%)$ \\
\hline & Unknown without bacteremia & 75 & $46(4.3 \%)$ & $26(5.1 \%)$ & $3(2.2 \%)$ \\
\hline & Viral/systemic & 42 & $31(2.9 \%)$ & $11(2.2 \%)$ & $0(0.0 \%)$ \\
\hline & Unknown with bacteremia & 23 & $11(1.0 \%)$ & $8(1.6 \%)$ & $4(3.0 \%)$ \\
\hline & Central nervous system & 18 & $6(0.6 \%)$ & $7(1.4 \%)$ & $5(3.7 \%)$ \\
\hline & Cardiovascular & 11 & $7(0.7 \%)$ & $4(0.8 \%)$ & $0(0.0 \%)$ \\
\hline \multirow[t]{4}{*}{ SIRS } & Pulse rate & 1314 & $807(75.2 \%)$ & $392(77.5 \%)$ & $115(85.8 \%)$ \\
\hline & Temperature & 968 & $639(59.6 \%)$ & $263(52.0 \%)$ & $66(49.3 \%)$ \\
\hline & Respiratory rate & 1071 & $631(58.8 \%)$ & $343(67.8 \%)$ & 97 (72.4\%) \\
\hline & Leucocyte count & 1228 & $760(70.8 \%)$ & $368(72.7 \%)$ & $100(74.6 \%)$ \\
\hline \multirow[t]{3}{*}{ SIRS positive criteria, $\mathrm{N}$} & 2 & 815 & $523(48.7 \%)$ & $240(47.4 \%)$ & $52(38.8 \%)$ \\
\hline & 3 & 641 & 409 (38.1\%) & $178(35.2 \%)$ & $54(40.3 \%)$ \\
\hline & 4 & 257 & $141(13.1 \%)$ & $88(17.4 \%)$ & $28(20.9 \%)$ \\
\hline \multirow[t]{7}{*}{ Site of organ failure } & CNS & 333 & $166(15.5 \%)$ & 116 (22.9\%) & 51 (38.1\%) \\
\hline & Metabolic & 226 & $129(12.0 \%)$ & 69 (13.6\%) & 28 (20.9\%) \\
\hline & Cardiovascular & 100 & $58(5.4 \%)$ & $33(6.5 \%)$ & $9(6.7 \%)$ \\
\hline & Respiratory & 709 & 471 (43.9\%) & 194 (38.3\%) & 44 (32.8\%) \\
\hline & Renal & 106 & $67(6.2 \%)$ & $31(6.1 \%)$ & $8(6.0 \%)$ \\
\hline & Hepatic & 55 & 40 (3.7\%) & $12(2.4 \%)$ & $3(2.2 \%)$ \\
\hline & Coagulation & 209 & $130(12.1 \%)$ & 55 (10.9\%) & 24 (17.9\%) \\
\hline
\end{tabular}




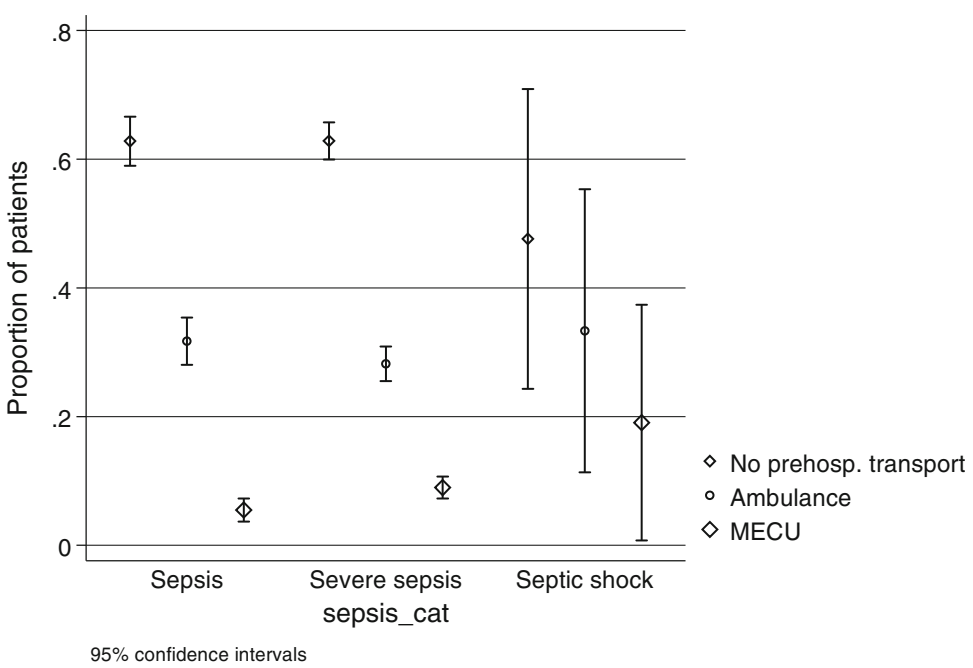

Fig. 1 Mode of transport for patients with sepsis, severe sepsis or septic shock, arriving to an Acute Medical Unit

assigned a high priority level [1]. One study describing the presentations of sepsis found primarily: Deterioration, physical signs and symptoms and difficulties establishing satisfactory contact with the patient [4]. Septic patients presenting with decreased general condition had less favorable outcome [34], and the risk of having an EMS dispatched as low priority doubled among patients with non-specific complaints [35]. Furthermore patients with decreased general condition in the emergency department, had a four-fold risk of suffering an in-hospital death [36]. To what extent sepsis patients were categorized by the dispatch center as having unclear problems, or presented with decreased general condition, were not part of our study. While

Table 2 Thirty-day mortality and Hazard-Ratio for sepsis patients arriving without public prehospital transport, ambulance or MECU to an Acute Medical Unit

\begin{tabular}{|c|c|c|c|c|c|}
\hline & $\mathrm{N}$ & 30-day mortality & Crude HR & $\begin{array}{l}\text { Adjusted HR } \\
\text { (gender and age) }\end{array}$ & $\begin{array}{l}\text { Adjusted HR } \\
\text { (all variables) }\end{array}$ \\
\hline \multicolumn{6}{|l|}{ Gender } \\
\hline Female & 920 & $132(14.3 \%)$ & 1.00 (Ref.) & 1.00 (Ref.) & 1.00 (Ref.) \\
\hline Male & 793 & $113(14.2 \%)$ & $0.99(0.77-1.28)$ & $1.02(0.79-1.31)$ & $0.96(0.74-1.23)$ \\
\hline Age & & & $1.05(1.04-1.06)$ & $1.05(1.04-1.06)$ & $1.04(1.03-1.06)$ \\
\hline \multicolumn{6}{|l|}{ Charlson Comorbidity Index } \\
\hline 0 & 570 & $56(9.8 \%)$ & 1.00 (Ref.) & 1.00 (Ref.) & 1.00 (Ref.) \\
\hline $1-2$ & 415 & $47(11.3 \%)$ & $1.15(0.78-1.70)$ & $0.76(0.51-1.12)$ & $0.79(0.53-1.17)$ \\
\hline$>2$ & 728 & $142(19.5 \%)$ & $2.08(1.52-2.83)$ & $1.23(0.90-1.68)$ & $1.26(0.92-1.73)$ \\
\hline \multicolumn{6}{|l|}{ No. organ dysfunct. per patient } \\
\hline 1 & 621 & $38(6.1 \%)$ & & & \\
\hline 2 & 651 & $79(12.1 \%)$ & $4.46(3.01-6.60)$ & $3.34(2.25-4.96)$ & $3.18(1.23-8.22)$ \\
\hline $3+$ & 300 & $73(24.3 \%)$ & $7.14(4.49-11.34)$ & $5.03(3.16-8.02)$ & $4.88(1.90-12.50)$ \\
\hline \multicolumn{6}{|l|}{ Arrival category } \\
\hline Without public prehospital transport & 1,073 & $136(12.7 \%)$ & 1.00 (Ref.) & 1.00 (Ref.) & 1.00 (Ref.) \\
\hline Ambulance & 506 & 81 (16.0\%) & $1.30(0.98-1.71)$ & $1.23(0.93-1.62)$ & $1.30(0.98-1.71)$ \\
\hline MECU & 134 & 28 (20.9\%) & $1.76(1.17-2.65)$ & $1.70(1.13-2.55)$ & $1.76(1.16-2.66)$ \\
\hline \multicolumn{6}{|l|}{ Sepsis category } \\
\hline Sepsis & 621 & $38(6.1 \%)$ & 1.00 (Ref.) & 1.00 (Ref.) & 1.00 (Ref.) \\
\hline Severe sepsis & 1,071 & 199 (18.6\%) & $3.30(2.33-4.66)$ & $2.62(1.85-3.71)$ & $9.51(1.96-46.15)$ \\
\hline septic shock & 21 & $8(38.1 \%)$ & $8.23(3.84-17.64)$ & 7.39 (3.44-15.87) & $8.99(2.13-38.02)$ \\
\hline
\end{tabular}


symptoms as fever, headache, breathing difficulties, unconsciousness and unclear problem are included in the Danish dispatch system, specific sepsis-related symptoms and descriptions are not [37]. As it is possible that improvement in the very early chain of care in sepsis, treatment could hopefully start even earlier [38]. We hope that future studies including symptom presentation at dispatch, could improve the diagnostic process and facilitate better care of patients with sepsis of any severity. Basis for further research could be case studies on septic patients', assigned different modes of transport, to increase dispatch-system understanding.

As a secondary aim, we observed a 30-day mortality for patients with sepsis of any severity arriving without public prehospital transport at $12.7 \%$, with ambulance $16 \%$ and with MECU 20.9\%. Other studies have focused on 28-day mortality and in-hospital mortality for patients with sepsis. These studies reported mortality rates at $15-20 \%$ for patients transported by EMS [22, 39, 40] and $6-7 \%$ for patients arriving without EMS transport $[22,40]$. According to our study and previous studies of patients with sepsis of any severity, mortality changes by mode of arrival. This is most probably caused by the ability of the dispatcher to better discover more serious cases and thus dispatch a suitable resource (MECU and/ or ambulance) to these patients. However, we believe there is an even need for greater consistency in the handling of all patients with sepsis, as we found septic patients at any severity at arrival, regardless of transportation mode.

\section{Study strengths}

Due to the uniformly organized Danish public healthcare system, we could identify all patients included in the study. Thus, we present a study with a full medical record including follow up. Manual chart review using a structured protocol was used to collect data regarding the presence of infections and type of transport. Registration of all MECU transports and sampling of paper files identified all ambulance transport. The hospital investigated in this study serves as the primary hospital (and the only hospital) in a well-defined catchment area.

\section{Limitations}

The current work was a single-center study from an acute medical unit at Odense University Hospital. The results may not necessarily be generalized to other hospitals. Moreover, when we compared with studies performed in other countries, the generalizability may be difficult, because of structure differences, differences in which patients have access to the health care system and where the economic resources are focused. Another definition of sepsis would alter the results. Finally there might have been some missed ambulance records, but the number is expected to be limited.

\section{Conclusions}

A substantial proportion of patients with severe sepsis and septic shock arrived to the hospital without public pre-hospital transport, but the proportion of patients with ambulance or MECU transport increased by disease severity. The mortality and hazard-ratio changed by mode of pre-hospital transport, with the highest rate in the MECU-transported patients.

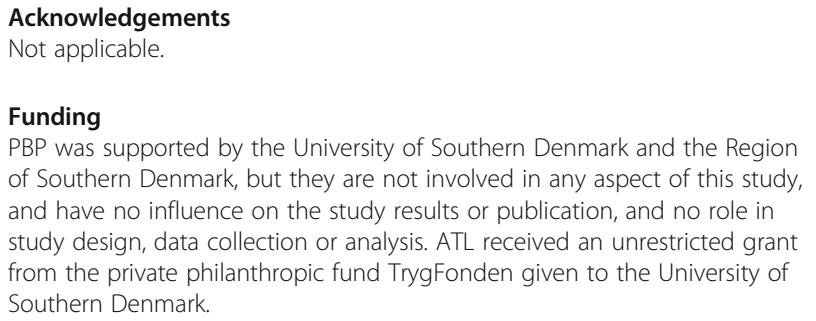

\section{Availability of data and materials}

The data that support the findings of this study are available on request from the corresponding author PBP. The data are not publicly available due to legal restrictions, and the standard terms for research projects and Danish Act on Processing of Personal Data define the rules of data sharing.

\section{Authors' contributions}

Idea and design: PBP ATL. Analyzed the data: DPH. Contributed materials: DPH SM ATL. Wrote the paper: PBP DPH SM ATL. All authors read and approved the final manuscript.

\section{Competing interests}

The authors declare that they have no competing interests.

Consent for publication

Not applicable.

\section{Ethics approval and consent to participate}

In compliance with Danish law, the study was approved by the Danish Data Protection Agency (J No 2008-58-0035), and patient record access was approved by the Danish National Board of Health (J No 3-3013-35). No further ethical approval is needed for register-based studies in Denmark.

\section{Publisher's Note}

Springer Nature remains neutral with regard to jurisdictional claims in published maps and institutional affiliations.

\section{Author details \\ ${ }^{1}$ Department of Emergency Medicine, Institute of Clinical Research, University of Southern Denmark \& Odense University Hospital, Odense C DK-5000, Denmark. ${ }^{2}$ Department of Emergency Medicine \& Department of Respiratory Medicine, Odense University Hospital, Odense C DK-5000, Denmark. \\ ${ }^{3}$ Department of Anesthesiology and Intensive Care Medicine, Odense University Hospital, Odense C DK-5000, Denmark. ${ }^{4}$ Department of Emergency Medicine, Institute of Clinical Research, University of Southern Denmark \& Odense University Hospital, Odense C DK-5000, Denmark.}

Received: 7 December 2016 Accepted: 4 May 2017

Published online: 12 May 2017

\section{References}

1. Møller TP, Ersbøll AK, Tolstrup JS, Østergaard D, Viereck S, Overton J, Folke F, Lippert F. Why and when citizens call for emergency help: an observational 
study of 211,193 medical emergency calls. Scand J Trauma Resusc Emerg Med. 2015;23:88. doi:10.1186/s13049-015-0169-0.

2. Andersen MS, Carlsen HP, Christensen EF. Criteria-based emergency medical dispatch of ambulances fulfils goals. Dan Med Bull. 2011;58(12):A4336.

3. Danish Regions and The Laerdal Foundation for Acute Medicine. Dansk Indeks for Akuthjælp version 1.4. 2013. Available at http://docplayer.dk/ 2708588-Dansk-indeks-for-akuthjaelp-amk-vagtcentralernes-vaerktoej-forvisitation-til-praehospitale-ressourcer.html. Accessed 5 Dec 2016.

4. Bohm K, Kurland L, Bartholdson S, Castrèn M. Descriptions and presentations of sepsis - A qualitative content analysis of emergency calls. Int Emerg Nurs. 2015;23(4):294-8. doi:10.1016/j.ienj.2015.04.003. Epub 2015 May 29.

5. Singer M, Deutschman CS, Seymour CW, Shankar-Hari M, Annane D, Bauer M, Bellomo R, Bernard GR, Chiche JD, Coopersmith CM, Hotchkiss RS, Levy MM, Marshall JC, Martin GS, Opal SM, Rubenfeld GD, van der Poll T, Vincent $\mathrm{J}$, Angus DC. The Third International Consensus Definitions for Sepsis and Septic Shock (Sepsis-3). JAMA. 2016;315(8):801-10. doi:10.1001/jama.2016.0287.

6. Dellinger RP, Levy MM, Rhodes A, Annane D, Gerlach H, Opal SM, Sevransky JE, Sprung CL, Douglas IS, Jaeschke R, Osborn TM, Nunnally ME, Townsend SR, Reinhart K, Kleinpell RM, Angus DC, Deutschman CS, Machado FR, Rubenfeld GD, Webb S, Beale RJ, Vincent JL, Moreno R. Surviving Sepsis Campaign Guidelines Committee including The Pediatric Subgroup. Surviving Sepsis Campaign: international guidelines for management of severe sepsis and septic shock, 2012. Intensive Care Med. 2013;39(2):165-228.

7. Angus DC, van der Poll T. Severe sepsis and septic shock. N Engl J Med. 2013;369(21):2063.

8. Shapiro NI, Wolfe RE, Moore RB, Smith E, Burdick E, Bates DW. Mortality in Emergency Department Sepsis (MEDS) score: a prospectively derived and validated clinical prediction rule. Crit Care Med. 2003;31(3):670-5.

9. Rivers E, Nguyen B, Havstad S, Ressler J, Muzzin A, Knoblich B, Peterson E, Tomlanovich M. EarlyGoal-Directed Therapy Collaborative Group. Early goal-directed therapy in the treatment of severe sepsis and septic shock. N Engl J Med. 2001;345(19):1368-77.

10. Henriksen DP, Laursen CB, Jensen TG, Hallas J, Pedersen C, Lassen AT. Incidence rate of community-acquired sepsis among hospitalized acute medical patients-a population-based survey. Crit Care Med. 2015;43(1):13-21.

11. Henriksen DP, Nielsen SL, Laursen CB, Hallas J, Pedersen C, Lassen AT. How well do discharge diagnoses identify hospitalised patients with communityacquired infections?-a validation study. PLoS One. 2014;9(3):e92891. doi:10. 1371/journal.pone.0092891. eCollection 2014.

12. Henriksen DP, Brabrand M, Lassen AT. Prognosis and risk factors for deterioration in patients admitted to a medical emergency department. PLoS One. 2014;9(4):e94649. doi:10.1371/journal.pone.0094649. eCollection 2014.

13. Henriksen DP, Laursen CB, Hallas J, Pedersen C, Lassen AT. Time to initial antibiotic administration, and short-term mortality among patients admitted with community-acquired severe infections with and without the presence of systemic inflammatory response syndrome: a follow-up study. Emerg Med J. 2015;32(11):846-53. doi:10.1136/emermed-2014-204565. Epub 2015 Mar 11.

14. Henriksen DP, Pottegård A, Laursen CB, Jensen TG, Hallas J, Pedersen C, Lassen AT. Risk factors for hospitalization due to community-acquired sepsis-a population-based case-control study. PLoS One. 2015;10(4): e0124838. doi:10.1371/journal.pone.0124838. eCollection 2015.

15. Henriksen DP, Pottegård $A$, Laursen $C B$, Jensen $T G$, Hallas J, Pedersen $C$, Lassen AT. Intermediate-term and long-term mortality among acute medical patients hospitalized with community-acquired sepsis: a population-based study. Eur J Emerg Med. 2016;2016:25.

16. Horan TC, Andrus M, Dudeck MA. CDC/NHSN surveillance definition of health care-associated infection and criteria for specific types of infections in the acute care setting. Am J Infect Control. 2008;36(5):309-32.

17. Frank L. Epidemiology. When an entire country is a cohort. Science. 2000; 287(5462):2398-9.

18. Pedersen CB. The Danish Civil Registration System. Scand J Public Health. 2011;39(7 Suppl):22-5.

19. Schmidt M, Schmidt SA, Sandegaard JL, Ehrenstein V, Pedersen L, Sørensen HT. The Danish National Patient Registry: a review of content, data quality, and research potential. Clin Epidemiol. 2015;7:449-90. doi:10.2147/CLEP. S91125. eCollection 2015. Review.

20. von Elm E, Altman DG, Egger M, Pocock SJ, Gøtzsche PC, Vandenbroucke JP. STROBE Initiative. The Strengthening the Reporting of Observational Studies in Epidemiology (STROBE) Statement: guidelines for reporting observational studies. Int J Surg. 2014;12(12):1495-9. doi:10.1016/j. ijsu.2014.07.013.
21. Band RA, Gaieski DF, Hylton JH, Shofer FS, Goyal M, Meisel ZF. Arriving by emergency medical services improves time to treatment endpoints for patients with severe sepsis or septic shock. Acad Emerg Med. 2011;18(9):934-40.

22. Groenewoudt M, Roest AA, Leijten FM, Stassen PM. Septic patients arriving with emergency medical services: a seriously ill population. Eur J Emerg Med. 2014;21(5):330-5.

23. Studnek JR, Artho MR, Garner Jr CL, Jones AE. The impact of emergency medical services on the ED care of severe sepsis. Am J Emerg Med. 2012;30(1):51-6.

24. Femling J, Weiss S, Hauswald E, Tarby D. EMS patients and walk in patients presenting with severe sepsis: differences in management and outcome. South Med J. 2014;107(12):751-6.

25. Ross DW, Caputo LM, Salottolo KM, Coniglio R, Mayfield TR, Mains CW, Carrick MM, Bar-Or D. Lights and Siren Transport and the Need for Hospital Intervention in Trauma Patients. Prehosp Emerg Care. 2016;20(2):260-5. doi:10.3109/10903127.2015.1076094. Epub 2015 Sep 18.

26. Møller TP, Andréll C, Viereck S, Todorova L, Friberg H, Lippert FK. Recognition of out-of-hospital cardiac arrest by medical dispatchers in emergency medical dispatch centres in two countries. Resuscitation. 2016; 109:1-8. doi:10.1016/j.resuscitation.2016.09.012.

27. Dami F, Heymann E, Pasquier M, Fuchs V, Carron PN, Hugli O. Time to identify cardiac arrest and provide dispatch-assisted cardio-pulmonary resuscitation in a criteria-based dispatch system. Resuscitation. 2015;97:27-33. doi:10.1016/j. resuscitation.2015.09.390. Epub 2015 Oct 1.

28. Rawshani A, Larsson A, Gelang C, Lindqvist J, Gellerstedt M, Bång A, Herlitz J. Characteristics and outcome among patients who dial for the EMS due to chest pain. Int J Cardiol. 2014;176(3):859-65. doi:10.1016/j.jicard.2014.08.004. Epub 2014 Aug 8.

29. Puolakka T, Strbian D, Harve H, Kuisma M, Lindsberg PJ, 5. Prehospital Phase of the Stroke Chain of Survival: A Prospective Observational Study. J Am Heart Assoc. 2016;5:e002808. doi:10.1161/JAHA.115.002808.

30. Wojner-Alexandrov AW, Alexandrov AV, Rodriguez D, Persse D, Grotta JC. Houston paramedic and emergency stroke treatment and outcomes study (HoPSTO). Stroke. 2005;36(7):1512-8. Epub 2005 Jun 16.

31. Yealy DM, Huang DT, Delaney A, Knight M, Randolph AG, Daniels R, Nutbeam T. Recognizing and managing sepsis: what needs to be done? BMC Med. 2015;13:98.

32. Smyth MA, Brace-McDonnell SJ, Perkins GD. Identification of adults with sepsis in the prehospital environment: a systematic review. BMJ Open. 2016; 6(8):e011218. doi:10.1136/bmjopen-2016-011218.

33. Christensen EF, Larsen TM, Jensen FB, Bendtsen MD, Hansen PA, Johnsen SP, Christiansen CF. Diagnosis and mortality in prehospital emergency patients transported to hospital: a population-based and registry-based cohort study. BMJ Open. 2016;6(7):e011558. doi:10.1136/bmjopen-2016-011558.

34. Wallgren UM, Antonsson VE, Castrén MK, Kurland L. Longer time to antibiotics and higher mortality among septic patients with non-specific presentations-a cross sectional study of Emergency Department patients indicating that a screening tool may improve identification. Scand J Trauma Resusc Emerg Med. 2016;24:1. doi:10.1186/s13049-015-0193-0.

35. Castrén M, Kurland L, Liljegard S, Djärv T. Non-specific complaints in the ambulance; predisposing structural factors. BMC Emerg Med. 2015;15:8. doi:10.1186/s12873-015-0034-5.

36. Djärv T, Castrén M, Mårtenson L, Kurland L. Decreased general condition in the emergency department: high in-hospital mortality and a broad range of discharge diagnoses. Eur J Emerg Med. 2015;22(4):241-6. doi:10.1097/MEJ. 0000000000000164.

37. Andersen MS, Johnsen SP, Sørensen JN, Jepsen SB, Hansen JB, Christensen EF. Implementing a nationwide criteria-based emergency medical dispatch system: a register-based follow-up study. Scand J Trauma Resusc Emerg Med. 2013:21:53. doi:10.1186/1757-7241-21-53.

38. Herlitz J, Bång A, Wireklint-Sundström B, Axelsson C, Bremer A, Hagiwara M, Jonsson A, Lundberg L, Suserud BO, Ljungström L. Suspicion and treatment of severe sepsis. An overview of the prehospital chain of care. Scand I Trauma Resusc Emerg Med. 2012;20:42.

39. Ibrahim I, Jacobs IG. Can the characteristics of emergency department attendances predict poor hospital outcomes in patients with sepsis? Singapore Med J. 2013;54(11):634-8.

40. Axelsson C, Herlitz J, Karlsson A, Sjöberg H, Jiménez-Herrera M, Bång A, Jonsson A, Bremer A, Andersson H, Gellerstedt M, Ljungström L. The Early Chain of Care in Patients with Bacteraemia with the Emphasis on the Prehospital Setting. Prehosp Disaster Med. 2016;30:1-6. 